\title{
Propofol Through Upregulating Caveolin-3 Attenuates Post-Hypoxic Mitochondrial Damage and Cell Death in $\mathrm{H} 9 \mathrm{C2}$ Cardiomyocytes During Hyperglycemia
}

\author{
Fan Denga Shuang Wang ${ }^{a} \quad$ Liangqing Zhang $^{a} \quad$ Xiang Xie $^{b}$ Shuyun Cai ${ }^{a}$ \\ Haobo Lic,d Gui-ling Xie ${ }^{a}$ Hui-Lai Miao ${ }^{a}$ Changmin Yange Xin Liu ${ }^{a}$ \\ Zhengyuan Xia ${ }^{a, b, c, d}$
}

${ }^{a}$ Department of Anesthesiology, Affiliated Hospital of Guangdong Medical University, Zhanjiang, Guangdong, 'bepartment of Anesthesiology, the Second Affiliated Hospital \&Yuying Children's Hospital of Wenzhou Medical University, Wenzhou, Zhejiang, 'State Key Laboratory of Pharmaceutical Biotechnology, Li KaShing Faculty of Medicine, the University of Hong Kong, Hong Kong, dDepartment of Anesthesiology, the University of Hong Kong, Hong Kong, eDepartment of Anesthesia, Hubei Province Jingmen City First Peoples Hospital, Jingmen, China

\section{Key Words}

Propofol • Caveolin-3 Ischemia-reperfusion $\cdot$ Diabetes $•$ Mitochondrial-dependent apoptosis

\begin{abstract}
Background/Aims: Hearts from diabetic subjects are susceptible to myocardial ischemia reperfusion (I/R) injury. Propofol has been shown to protect against myocardial I/R injury due to its antioxidant properties while the underlying mechanism remained incompletely understood. Thus, this study aimed to determine whether or not propofol could attenuate myocardial I/R injury by attenuating mitochondrial dysfunction/damage through upregulating Caveolin (Cav)-3 under hyperglycemia. Methods: Cultured rat cardiomyocyte H9C2 cells were subjected to hypoxia/reoxygenation $(H / R)$ in the absence or presence of propofol under high glucose $(H G)$, and cell viability, lactate dehydrogenase $(\mathrm{LDH})$ and mitochondrial viability as well as creatine kinase-MB (CK-MB), cardiac troponin I (cTnI) and intracellular adenosine triphosphate (ATP) content were measured with colorimetric Enzyme-Linked Immunosorbent Assays. Intracellular levels of oxidative stress was assessed using 2,7-dichlorodihydrofluorescein diacetate (DCF-DA) fluorescent staining and mitochondrial-dependent apoptosis was assessed by detecting mitochondrial membrane potential and the activation of apoptotic caspases 3 and 9. Results: Exposure of cells to HG without or with H/R both significantly increased cell injury, cell apoptosis and enhanced oxidative stress that were associated with mitochondrial dysfunction and decreased Cav-3 protein expression. All these changes were further exacerbated following $\mathrm{H} / \mathrm{R}$ under $\mathrm{HG}$. Administration of propofol at concentrations from 12.5 to $50 \mu \mathrm{M}$ but not $100 \mu \mathrm{M}$ significantly attenuated $\mathrm{H} / \mathrm{R}$ injury that was associated

F. Deng, S. Wang and L. Zhang contributed equally to this work.

Xin Liu

and Zhengyuan Xia

Department of Anesthesiology, Affiliated Hospital of Guangdong Medical University Zhanjiang, Guangdong, China; Department of Anesthesiology, The University of Hong Kong, (Hong Kong); E-Mail ljpp168@163.com/zyxia@hku.hk
\end{abstract}

KARGER 


\section{Cellular Physiology Cell Physiol Biochem 2017;44:279-292 \\ \begin{tabular}{ll|l} 
and Biochemistry Published online: November 09, 2017 & $\begin{array}{l}\text { (c) } 2017 \text { The Author(s). Published by S. Karger AG, Basel } \\
\text { www.karger.com/cpb }\end{array}$ \\
\hline
\end{tabular} \\ Deng et al.: Propofol Upregulates Cardiomyocyte Post-Hypoxic Caveolin-3}

with increased Cav-3 expression and activation of the prosurvival proteins Akt and STAT3 with the optimal protective effects seen at $50 \mu \mathrm{M}$ of propofol (P25). The beneficial effects of propofol(P25) were abrogated by Cav-3 disruption with $\beta$-methyl-cyclodextrin. Conclusion: Propofol counteracts cardiomyocyte $\mathrm{H} / \mathrm{R}$ injury by attenuating mitochondrial damage and improving mitochondrial biogenesis through upregulating Cav-3 during hyperglycemia.

(C) 2017 The Author(s)

Published by S. Karger AG, Basel

\section{Introduction}

Ischemic heart disease remains the leading cause of death in patients with cardiovascular diseases, particularly in patients with diabetes. Restoration of the coronary blood flow (reperfusion) is essential for the salvage of the ischemic heart, however, reperfusion itself may lead to lethal myocardium injury $[1,2]$, termed myocardial ischemia reperfusion (I/R) injury. Brief episodes of ischemia and reperfusion applied either before (ischemic preconditioning) or after (ischemic postconditioning) prolonged ischemia protects the hearts against myocardial I/R in non-diabetes. Similarly, administration of anesthetics such as sevoflurane, isoflurane, and propofol before or after prolonged ischemia confers cardioprotection against myocardial I/R injury, which is called anesthetic conditioning [3, 4]. However, accumulating evidences showed that the cardioprotective effects of ischemic preconditioning, ischemic postconditioning, or anesthetic conditioning were attenuated or abolished in hearts from diabetes. Interestingly, a most recent clinical trial study showed that infusion of clinically achievable high-dose propofol, a widely used intravenous anesthetic, during cardiopulmonary bypass in diabetic patients receiving coronary artery bypass grafting conferred cardioprotection manifested as reduced cardiac troponin I release and decreased major adverse cardiac events [5]. We previously showed that propofol when applied before and during ischemia, and early reperfusion, dose-dependently reduced lipid peroxidation and conferred cardioprotection in isolated rat heats [6]. Also, propofol, when applied at clinically achievable high doses, conferred cardioprotection in middle-aged animals with myocardial I/R [7]. These suggest that, when applied at a relatively higher dose, propofol may confer cardioprotection in hearts from diabetes. However, the mechanism whereby propofol confers cardioprotective effects against myocardial I/R injury, especially in hyperglycemia condition has not been fully elucidated.

Oxidative stress induced by burst production of reactive oxygen species (ROS) during reperfusion has been proven to be an important factor leading to and exacerbating myocardial I/R injury [8]. Excessive formation of ROS on the one hand reduces mitochondrial membrane potential, enhances mitochondrial permeability transition pore (MPTP) opening, and on the other hand reduces mitochondrial biogenesis (e.g., reduces ATP production), which jointly lead to mitochondrial dysfunction and mitochondrial apoptosis [9] that may in turn further increase ROS production and exacerbatemyocardial I/R injury. Thus, effective means that can protect mitochondrial dysfunction may confer cardioprotection against myocardial $\mathrm{I} / \mathrm{R}$ injury. Indeed, previous studies have shown that propofol protection of human myocardium against I/R injury was mediated by mitochondrial adenosine triphosphatesensitive potassium channels opening and mitochondrial respiratory chain complexes in in vitro models of cardiomyocytes of hypoxia/reoxygenation [10] and in patients undergoing coronary artery bypass grafting surgery with cardiopulmonary bypass [11]. However, it is still unclear how propofol attenuates mitochondrial dysfunction during myocardial I/R to confer cardioprotection and whether or not propofol confers cardioprotection in hearts from diabetes through mitochondria protection.

Caveolae are flask-like invaginations of the cell surface that have been identified as signaling epicenters. Within these microdomains, caveolins (Cav) are structural proteins of caveolae $[12,13]$, which interact with numerous signaling molecules (such as eNOS, PI3K, and MER/MRK etc.) that are required in cardiac protection initiated by a variety of cardioprotective interventions (e.g., ischemic preconditioning [14] and anesthetic preconditioning [15]). Cardiac I/R tolerance parallels the expression of Cav-3, the cardiac- 


\section{Cellular Physiology Cell Physiol Biochem 2017;44:279-292 \begin{tabular}{l|l|l}
\hline and BOI: 10.1159/000484680 & $\begin{array}{l}\text { C } 2017 \text { The Author(s). Published by S. Karger AG, Basel } \\
\text { www.karger.com/cpb }\end{array}$
\end{tabular} \\ Deng et al.: Propofol Upregulates Cardiomyocyte Post-Hypoxic Caveolin-3}

specific isoform of Cav. Deletion of Cav-3 reduces, whereas Cav-3 overexpression improves mitochondrial function [16] and attenuates myocardial I/R injury [17]. Interestingly, in airway smooth muscle cells, propofol mediated inhibition of cellular contracture was diminished in cells with Cav-1 gene knock-down [18], suggesting that Cav may play critical roles in propofol beneficial effects. However, we and others have found that cardiac Cav-3 is reduced in hearts from diabetic animals $[19,20]$ and that this reduction was associated with increased mitochondrial dysfunction [21] and exacerbated myocardial I/R injury [19, 22]. It is unknown whether or not Cav-3 plays a role in propofol cardioprotection in hearts from diabetes.

Therefore, we hypothesized that propofolmay protect hearts from diabetes against myocardial I/R injury by attenuating mitochondrial dysfunction and its does so by upregulating cardiac Cav-3.

\section{Materials and Methods}

\section{Reagents and antibodies}

In order to exclude the interference of fat emulsion, pure propofol was purchased from Sigma. Reagents used in the experiment wereas follows: Dulbecco's modified Eagle's medium (DMEM), Fetal bovine serum (FBS), penicillin, streptomycin, trypsin-EDTA (GIBCO Laboratories, Grand Island, New York, USA) and dimethylsulfoxide (DMSO). Propofol powder is dissolved into DMSO and then diluted with PBS; the final concentration of DMSO shall be less than $0.1 \%$, so as to ensure that the cell function and experimental detection will not be affected. Antibodies used in the experiment were as follows: anti-beta-Actin antibody (Santa Cruz, sc-47778), anti-caspase-3 antibody (sigma, SAB4503291), anti-caspase-9 antibody (sigma,SAB3500405), anti-Hypoxia inducible factor (HIF)-1alpha antibody (sigma, SAB5200017), antibax antibody (50599-2-Ig, Proteintech, China), anti-bcl2 antibody (12789-1-AP, Proteintech, China), antiCytochrome-c antibody (66264-1-Ig, Proteintech, China), anti-COXIV antibody (11242-1-AP, Proteintech, China) and anti-caveolin-3 antibody (sigma, AV09021). Kits used in the experiment are as follows: cell counting kit-8 (CCK-8) (Shanghai Tongren, CK04), mitochondrial viability stain (ab129732, abcam, UK), lactate dehydrogenase (LDH) assay kit (A020-2, Nanjing Jiancheng Bioengineering Institute, Nanjing, China), reactive oxygen species (ROS) kit, intracellular malondialdehyde (MDA) kit and total superoxide dismutase (T-SOD) kit (all from Nanjing Jiancheng Bioengineering Institute, Nanjing, China), ATP assay kit (Nanjing Jiancheng Bioengineering Institute, A095-1, Nanjing, China), rat creatine kinase-MB (CK-MB) elisa kit (CSB-E14403r, cusabio, China), rat cardiac troponin I (cTnI) elisa kit (CSB-E08594r, cusabio, China) and JC-1 mitochondrial membrane potential detection kit (bestbio, BB-4105-3, Shanghai, China).

\section{Cell culture}

H9C2 embryonic rat heart-derived (ventricular) cells (myoblasts) from ATCC, at the passages 5 to 10, were used in this study. H9C2 cells $\left(2 * 10^{6-7}\right.$ cells per well in six well tissue culture plate) were cultured in an incubator with DMEM+10\% fetal bovine serum (FBS) +100 units $/ \mathrm{mL}$ penicillin and $100 \mathrm{mg} / \mathrm{mL}$ streptomycin under the condition of $37^{\circ} \mathrm{C} 5 \% \mathrm{CO}_{2}$ and $95 \% \mathrm{O}_{2}$.

\section{H9C2 Cell Hypoxia/Reoxygenation $(H / R)$ model}

Hypoxic environment was a moist and closed plastic vessel. The cells were placed onto the hypoxic vessel, filled with the mixture of $94 \% \mathrm{~N}_{2}, 5 \% \mathrm{CO}_{2}$ and $1 \% \mathrm{O}_{2}$ for 5 minutes (min), and subjected to hypoxia for 12 hours (h) under $37^{\circ} \mathrm{C}$ and reoxygenated for $6 \mathrm{~h}$ by exposing the cells to a cell incubator. The cells were assigned to the following groups: Normal control (NC) group which did not undergo H/R and were always cultured in the normal sugar medium $+10 \%$ FBS; High glucose (HG) group, H/R under normal glucosegroup, H/R under high glucose group, and propofol treated groups in which cells were treated with various concentrations $(12.5,25,50$, and $100 \mathrm{uM}$ ) of propofol (i.e., P12.5, P25, P50, P100) or the solvent DMSO group (D100, DMSO at $100 \mathrm{uM}$ ) respectively during reoxygenation for $6 \mathrm{~h}$. Cells in all these groups were cultured in the normal glucose $(1 \mathrm{~g} / \mathrm{L})$ medium $+10 \% \mathrm{FBS}$ to the density of about $50 \%$, then cultured in the high glucose $(4.5 \mathrm{~g} / \mathrm{L})$ medium $+10 \% \mathrm{FBS}$ for $48 \mathrm{~h}$, and then switched to culture in the glucose and serum free medium before inducing hypoxia. After $12 \mathrm{~h}$ of hypoxia, high glucose medium $+10 \%$ FBS was 


\section{Cellular Physiology Cell Physiol Biochem 2017;44:279-292 \begin{tabular}{l|l|l}
\hline and Biochemistry 10.1159/000484680 & $\begin{array}{l}\text { C } 2017 \text { The Author(s). Published by S. Karger AG, Basel } \\
\text { www.karger.com/cpb }\end{array}$
\end{tabular} \\ Deng et al.: Propofol Upregulates Cardiomyocyte Post-Hypoxic Caveolin-3}

used for $6 \mathrm{~h}$ during reoxygenation. After the completion of the above optimal dose-finding study, a separate set of study was further conducted which employed the most effectively concentration of propofol (i.e., 25 $\mathrm{uM}$ ) identified. Cells were treated without or with the Cav- 3 inhibitor/disruptor methyl- $\beta$-cyclodextrin (5 $\mathrm{mmol} / \mathrm{L}$ ) for $40 \mathrm{~min}$ before inducing hypxoxia to explore the role of Cav-3 in propofol(25 $\mathrm{uM}$ ) protective effects against $\mathrm{H} 9 \mathrm{C} 2$ cells $\mathrm{H} / \mathrm{R}$ injury under conditions of high glucose, and groups in which cells being treated with NC, HG, HG plus H/R and D100 were repeated in this part of study.

\section{Cell viability measured by CCK-8 assay and mitochondria viability stain}

The agent in cell counting kit (CCK) can be restored by dehydrogenase in mitochondria and then produces highly water-soluble orange formazan product in the case of electronic coupling agent presence. Mitochondrial Viability Stain (ab129732) is a fluorometric/colorimetric assay that uses an indicator dye to measure oxidation-reduction reactions which principally occur in the mitochondria of live cells. OD values resulting from CCK-8 staining and from mitochondrial viability staining were, respectively, measured using a microplate reader at a wavelength in the $450 \mathrm{~nm}$ (CCK-8) and $570 \mathrm{~nm}$ (mitochondria viability) which indirectly reflects the viabilities of cells and mitochondria.

\section{Detection of Lactate dehydrogenase}

Lactate dehydrogenase (LDH) is aglycolytic enzyme involved in pyruvate to lactic acid metabolism, which presents in almost all tissues or cytoplasm in the body. When the cell membrane damages, LDH is rapidly released. So, we determined the degree of cell damage by detecting LDH activity in cell culture supernatant. Cell culture medium was processed according to the instructions of the manufacture and then OD value was measured using a microplate reader at a wavelength in the $450 \mathrm{~nm}$ which indirectly reflected the degree of cell damage.

\section{Detection of CK-MB and $c T n I$}

CK-MB and cTnI release will increase significantly when myocardial injury occurs and they are markers of myocardial cellular injury. Briefly, reagents, samples and standards were prepared as instructed by producers of the assay kits. Then $100 \mu \mathrm{l}$ standard or samples were added to each well for $2 \mathrm{~h}$ at $37^{\circ} \mathrm{C}$ Two hours later, the liquid in each well was removed and added with $100 \mu \mathrm{l}$ biotin-antibody (1x) to incubate for 1 hour at $37^{\circ} \mathrm{C}$ Thereafter, the wells were washed 3 times before adding 100 $\mu$ HRP-avidin (1X) to each well for 1 hour at $37^{\circ} \mathrm{C}$. After removing the liquid of each well and washing for 5 times, $90 \mu \mathrm{l}$ TMB substrate was added to each well for $15-30 \mathrm{~min}$ at $37^{\circ} \mathrm{C}$ in dark. At last, the reaction was stopped by adding $50 \mu \mathrm{l}$ stop solution to each well and read at $450 \mathrm{~nm}$ within $5 \mathrm{~min}$.

\section{Detection of ROS}

Intracellular ROS was assessed using 2, 7-dichlorodihydrofluorescein diacetate (DCF-DA) staining and quantified by a flow cytometer. DCFH-DA is the most commonly used and most sensitive intracellular ROS detection probe. DCFH-DA has no fluorescence and is hydrolyzed into DCFH (dichlorodihydrofluorescein) by esterase after entering the cell. In the presence of ROS, DCFH is oxidized to the enhanced green fluorescent substance DCF that cannot penetrate the cell membrane, and its fluorescence intensity is directly proportional to the level of intracellular ROS. The DCFH-DA at working concentration was added into the medium, incubated for $30 \mathrm{~min}$ under $37^{\circ} \mathrm{C}$, followed by cell digestion for 2-3 min by trypsin; the medium with $10 \%$ FBS was added to terminate the cell digestion, and then the cell suspension was prepared and centrifuged at $1000 \mathrm{~g}$ for 5 min to collect cells, which were then washed for 1-2 times with PBS. It was used for FACS detection after cell sediments were suspended in PBS. The optimal excitation wavelength of fluorescence is 500 and $485 \mathrm{~nm}$, and the optimal emission wavelength is $525 \mathrm{~nm}$.

\section{Measurement of Intracellular Malondialdehyde (MDA) and total superoxide dismutase (T-SOD)}

The level of SOD activity indirectly reflects the ability of the body to scavenge ROS, while the level of MDA indirectly reflects the severity of cells attacked by ROS. The MDA is the degradation products of lipid peroxide which can condense with thiobarbituric acid (TBA), resulting in a red product which has the maximum absorption peak at $532 \mathrm{~nm}$. Intracellular superoxide anions can oxidize hydroxylamine, resulting in nitrite which shows purplish red under the action of chromogenic agent. The samples in all groups were added to 96-well plates and measured with commercial assay kits for SOD (Nanjing Jiancheng Bioengineering 


\section{Cellular Physiology Cell Physiol Biochem 2017;44:279-292

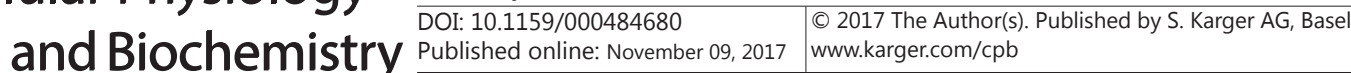 \\ Deng et al.: Propofol Upregulates Cardiomyocyte Post-Hypoxic Caveolin-3}

Institute, A001-01, Nanjing, China) and for MDA ((Nanjing Jiancheng Bioengineering Institute, A003-04, Nanjing, China), respectively as described [23].

\section{Measurement of Intracellular ATP}

Adenosine 5'-triphosphate (ATP) is the basic carrier of energy conversion in vivo and is the most important energy molecules in cells involved in various physiological and pathological processes. Normally, ATP levels will fall when cells befall apoptosis, necrosis or other toxic state, and decreased ATP levels indicate mitochondrial dysfunction or decline. During apoptosis, ATP levels often drop simultaneously with the decline of mitochondrial membrane potential. ATP content was measured using ATP assay kit (Nanjing Jiancheng Bioengineering Institute, A095-1, Nanjing, China) following the instruction.

\section{Cell mitochondria isolation}

After digestion with trypsin, H9C2 were collected by centrifugation and were gently resuspended with ice-cold PBS. Then the cells were counted and centrifuged at $600 \mathrm{~g}, 4^{\circ} \mathrm{C}$ for $5 \mathrm{~min}$. The supernatant was discarded and 1-2.5 ml cell mitochondria isolation reagent was used to gently resuspend cells, then the cells were placed in ice for 10-15 min. After homogenization and repeated centrifugation, the precipitate was isolated mitochondria after careful removal of the supernatant [10]. And the amount of cytochrome $\mathrm{C}$ in the supernatant reflected the release of mitochondrial cytochrome $\mathrm{C}$ into the cytoplasm.

\section{Assessment of mitochondrial membrane potential with JC-1 staining}

Decrease of mitochondrial membrane potential marks the early apoptosis. In case of higher mitochondrial membrane potential, JC-1 aggregates in the mitochondrial matrix, forming a polymer with its maximum emission wavelength at $590 \mathrm{~nm}$ when excited at $488 \mathrm{~nm}$, and red fluorescence can be emitted. In case of lower mitochondrial membrane potential, JC-1 cannot aggregate in the mitochondrial matrix and acts as monomer with its maximum emission wavelength at $527 \mathrm{~nm}$ when excited at $488 \mathrm{~nm}$, and green fluorescence can be emitted. In this way, changes of mitochondrial membrane potential can be detected based on the changes of fluorescent color. Therefore, the application of JC-1 dye has been widely used for detecting mitochondrial depolarization occurring in apoptosis. Sample cells were collected and washed twice with PBS; the cells were collected through centrifugation, then resuspended in $500 \mu \mathrm{L}$ JC-1 staining solution and incubated for $15 \mathrm{~min}$ in an incubator with $5 \% \mathrm{CO}_{2}$ under $37{ }^{\circ} \mathrm{C}$; the cells were collected again through centrifugation, and then resuspended in $500 \mu \mathrm{L}$ preheated incubation buffer. The results were detected and analyzed by a flow cytometer as we described [21].

\section{Assessment of mitochondrial membrane permeability with MPTP}

Mitochondria permeability transition pores (MPTP) are non-specific calcium-dependent channel composed of inner and outer mitochondrial membrane component. MPTP will open and the permeability of the mitochondrial membrane will be significantly altered when cells are under the state of apoptosis, necrosis, oxidative stress and other stimulations, which will lead to the release of cytochrome $\mathrm{C}$ and other mitochondrial contents and cause significant fall of mitochondrial membrane potential. Calcein was used to detect the state of MPTP through the change in fluorescence of mitochondria.

\section{Protein assay with Western blot}

Western blot was used for quantitative detection of Caspase-3, Caspase-9, HIF-1alpha, Bax, Bcl2, Cytochrome-c, COX IV, p-AKT, p-STAT3, AKT, STAT3 and caveolin-3 protein expression. Protein samples prepared were respectively added to $10 \%$ SDS polyacrylamide gel for electrophoresis, and then transferred to a PVDF membrane. Thereafter, the PVDF membrane was incubated overnight together with antibody at $4^{\circ} \mathrm{C}$. On the next day, the PVDF membrane was placed on a shaker for rewarming $30 \mathrm{~min}$ at room temperature, and washed with PBS for 10 mins*4 times; then the PVDF membrane was incubated with corresponding secondary antibodies in the shaker at room temperature for $4 \mathrm{~h}$ and washed with PBS for 10 mins* 4 times before exposure, and analyzed as described [24].

Data analysis and statistics

All data, which were normally distributed, were presented as means \pm SD (normal distribution) and analyzed using SPSS 13.0 software (SPSS, Chicago, IL, USA). The differences between groups were 
Fig. 1. H9C2 cells injury and oxidative stress induced by high glucose $(4.5 \mathrm{~g} / \mathrm{L}) \quad(\mathrm{HG})$ or/and hypoxia reoxygenation (H/R). A: Cell viability; B: Lactate dehydrogenase (LDH); C: Creatine Kinase-MB (CKMB); D: Cardiac troponin I (cTnI); E: Level of malondialdehyde (MDA); F: Total superoxide dismutase (T-SOD) activity. Data are mean \pm SD with $\mathrm{n}=6$ per group, ${ }^{*} \mathrm{P}<0.05,{ }^{* *} \mathrm{P}<0.01$.

analyzed by one-way ANOVA (normal distribution), and multiple comparisons were performed by the Bonferroni correction. Differences with $\mathrm{p}<0.05$ were considered statistically significant.

\section{Results}

H9C2 cardiomyocytes injury and oxidative stress induced by high glucose or/ and $H / R$

We conducted studies
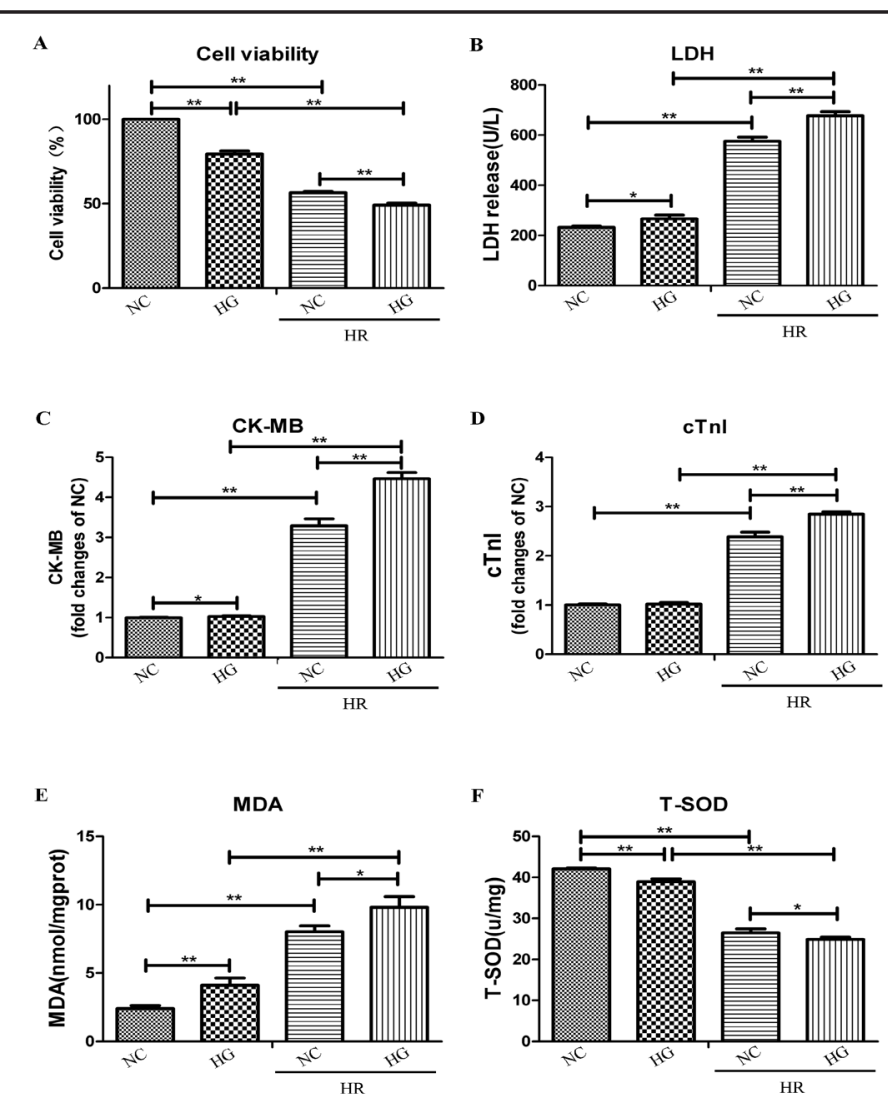

to confirm whether or not

hypoxia/reoxygenation (HR) under high glucose (HG) condition cause more severe cellular damage than under normal glucose condition (NC group). As shown in Fig. 1, high glucose (HG) and H/R exposure both caused significant cell injury evidenced as reduced cell viability, increased LDH, CKMB and cTnI releases (Fig. 1A to D) and significantly increased oxidative stress evidenced as significant increase in MDA and reduction in total SOD activity (Fig. 1. E and F).

Propofol dose-selectively attenuated post-hypoxic cell injury in H9C2 cardiomyocytes exposed to high glucose

As shown in Fig. 2, high glucose (HG)exposure caused significant cell injury manifested as reduction in cell viability (Fig. 2A) and increases in LDH, CK-MB, and cTnI (Fig. 2B-D) (all $P<0.05 v s$. group NC), which were associated with elevated cell apoptosis evidenced by increased Bax/Bcl-2 ratio and enhanced capases-3 expression (Fig. 2E-F). Cell injury was further exacerbated by $\mathrm{H} / \mathrm{R}$ under $\mathrm{HG}$ evidenced by reduction in cell viability and increases in LDH, CK-MB, and cTnI (Fig. 2A-D) (all $P<0.05$, HGvs.H/R+HG) and enhanced cell apoptosis (Fig. 2E-F). All these changes were reversed or prevented by propofol dose-dependently in the concentrations ranging from 12.5 to $50 \mu \mathrm{M}$ with the most profound protection at 25 $\mu \mathrm{M}$ (all $\mathrm{P}<0.05, \mathrm{HG}+\mathrm{H} / \mathrm{R}+\mathrm{P} 12.5$ or $\mathrm{HG}+\mathrm{H} / \mathrm{R}+\mathrm{P} 25 v s$. $\mathrm{HG}+\mathrm{H} / \mathrm{R}$ ) despite that all these related values in the $\mathrm{P} 25$ group remain significantly different from those in the HG group (all $\mathrm{P}<0.05$ ). However, no protective effect was observed when propofol concentration increased to 100 $\mu \mathrm{M}$.

Propofol dose-selectively attenuated post-hypoxic oxidative stressin cardiomyocytes exposed to high glucose

As shown in Fig. 3, HG exposure caused significant increase of oxidative stress manifested as enhanced ROS production (Fig. 3A-B) and lipid peroxidation product MDA formation (Fig. 
Fig. 2. Effects of different concentrations of propofol on hypoxia reoxygenation $(\mathrm{H} / \mathrm{R})$ injury in H9C2 cells exposed to high glucose (4.5 g/L) (HG). H9C2 cells were exposed to normal glucose (NG) or high glucose $(4.5 \mathrm{~g} / \mathrm{L})(\mathrm{HG})$ and subjected to $H / R$ in the absence or presence of propofol at concentrations 12.5 (P12.5), 25 (P25), 50 (P50), and $100 \mu \mathrm{M}$ (P100), or DMSO as control (D100). A: Cell viability; B: Lactate dehydrogenase (LDH); C: Creatine KinaseMB (CK-MB); D: Cardiac troponin I (cTnI); E: Bax to Bcl2 ratio; F: Caspase-3 protein expression; G: Representative images of protein expression. Data are mean \pm SD with $n=6$ per group, ${ }^{*} \mathrm{P}<0.05$, ${ }^{* *} \mathrm{P}<0.01$.

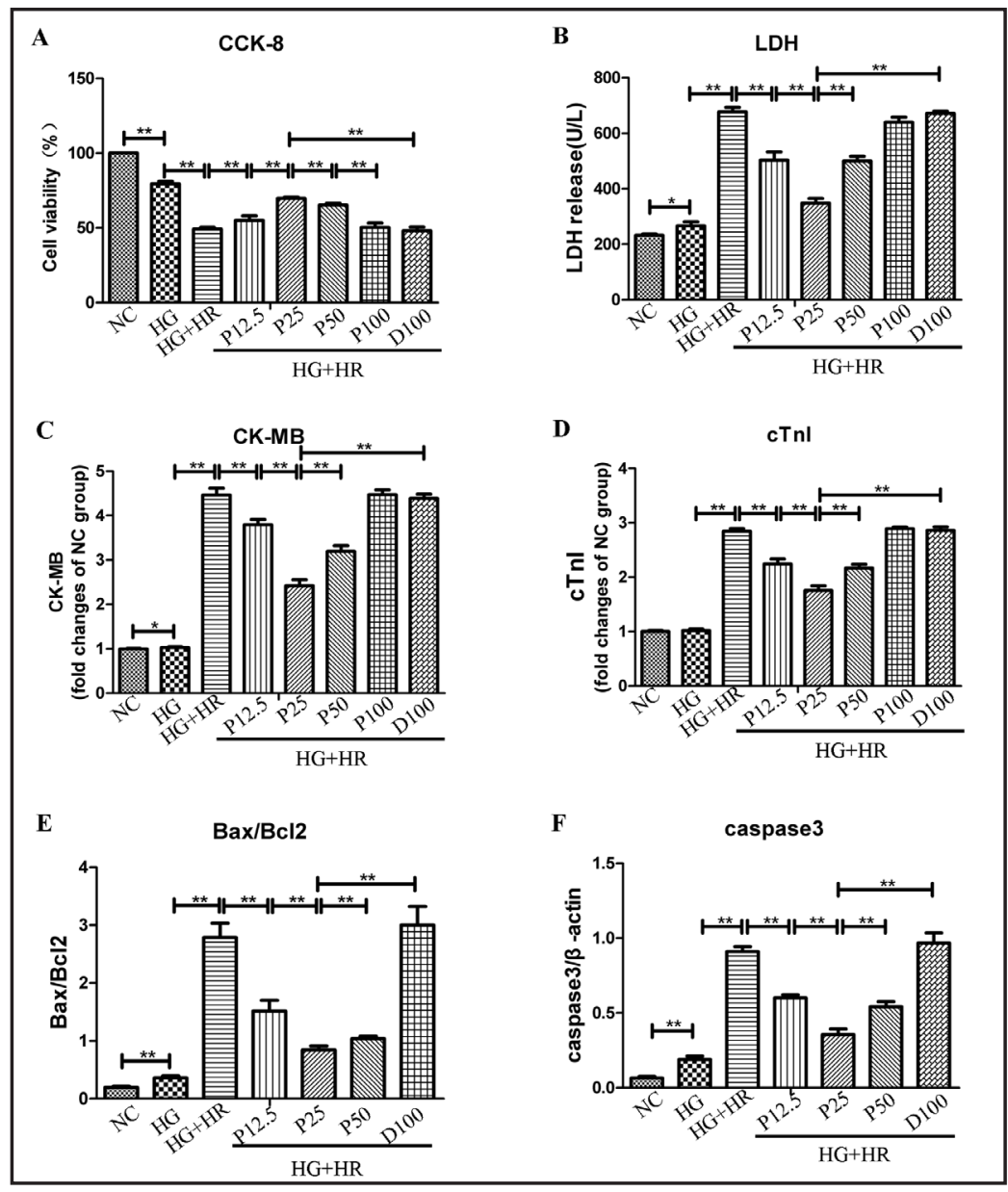

3C) that were associated with reduced total SOD (T-SOD) activity (Fig. 3D) (all $P<0.05$, HG vs. NC). Oxidative stress was further enhanced by H/R evidenced by increased ROS, enhanced MDA and reduced T-SOD activity (all $P<0.05, \mathrm{H} / \mathrm{R}+\mathrm{HG}$ s. HG). All these changes were attenuated by propofol dose-dependently in the concentrations ranging from 12.5 to $50 \mu \mathrm{M}$ with the most profound protection at $25 \mu \mathrm{M}$ (all $P<0.05, \mathrm{HG}+\mathrm{H} / \mathrm{R}+\mathrm{P} 12.5$ or $\mathrm{HG}+\mathrm{H} / \mathrm{R}+\mathrm{P} 25$ vs. $\mathrm{HG}+\mathrm{H} / \mathrm{R}$ ) (Fig. 3), while no effect was observed when propofol concentration increased to $100 \mu \mathrm{M}$. Propofol at $25 \mu \mathrm{M}$ (P25) did not completely prevent H/R induced increase in ROS production under $\mathrm{HG}(\mathrm{P}<0.05, \mathrm{HG}+\mathrm{HR}+\mathrm{P} 25$ vs. HG, Fig. $3 \mathrm{~B})$ but prevented $\mathrm{H} / \mathrm{R}$ induced increase in MDA with concomitant restoration of T-SOD (Fig. 3C \& D).

Propofol dose-selectively attenuated post-hypoxic mitochondrial dysfunction in cardiomyocytes exposed to high glucose

As shown in Fig. 4, HG exposure significantly reduced mitochondrial dysfunction manifested as decreased mitochondria viability (Fig. 4A), reduced mitochondrial membrane potential evidenced as increased number/percentage of cells that lost mitochondrial membrane potential (Fig. 4B), increased MPTP opening (Fig. 4C), and enhanced release of mitochondrial cytochrome $\mathrm{C}$ into the cytoplasma (Data not shown) and decreased mitochondrial cytochrome C protein expression (Fig. 4D), which were associated with decreased ATP production (Fig. 4E) and reduced caveolins-3 protein expression (Fig. 4F) (all $\mathrm{P}<0.05, \mathrm{HG}$ vs. NC). All these changes were further exuberated by $\mathrm{H} / \mathrm{R}$ under $\mathrm{HG}$ (all $\mathrm{P}<0.05$, $\mathrm{H} / \mathrm{R}+\mathrm{HG}$ vs. HG), while treatment with propofol dose-dependently (from $12.5 \mu \mathrm{M}$ to $50 \mu \mathrm{M}$ ) attenuated post-hypoxic mitochondrial dysfunction and improved mitochondrial biogenesis with the most profound protective effects seen at propofol concentration of $25 \mu \mathrm{M}$ that prevented HR induced reduction of cardiac ATP and Cav-3 under HG $(\mathrm{P}>0.05, \mathrm{HG}+\mathrm{HR}+\mathrm{P} 25$ 
Fig. 3. Effects of different concentrations of propofol on post-hypoxic oxidative stress in H9C2 cells exposed to HG ( $4.5 \mathrm{~g} / \mathrm{L})$. H9C2 cells were exposed to normal glucose (NG) or high glucose $(4.5 \mathrm{~g} / \mathrm{L})(\mathrm{HG})$ and subjected to $\mathrm{H} / \mathrm{R}$ in the absence or presence of propofol at concentrations 12.5 (P12.5), 25 (P25), 50 (P50), and $100 \mu \mathrm{M}$ (P100), or DMSO as control (D100). A and B: ROS formation assessed by DCF-DA fluorescence staining; C: Level of malondialdehyde (MDA); D: Total superoxide dismutase (T-SOD) activity. Data are mean \pm SD with $\mathrm{n}=6$ per group, ${ }^{*} \mathrm{P}<0.05,{ }^{* *} \mathrm{P}<0.01$.
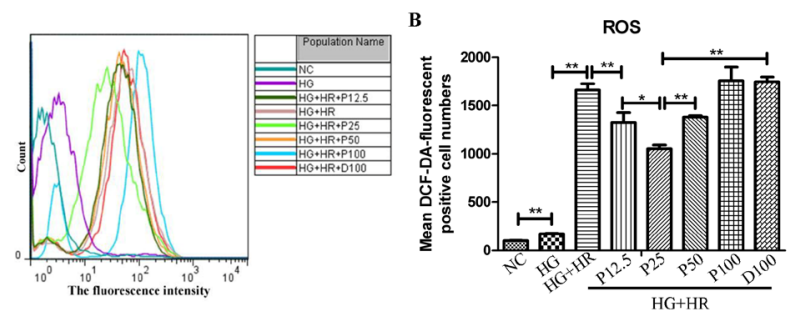

C

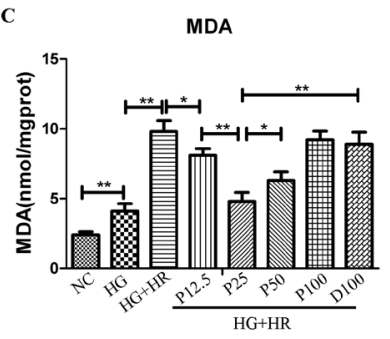

D

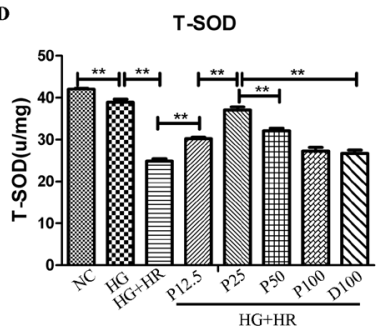

Fig. 4. Effects of different concentrations propofol on post-hypoxic mitochondrial function in H9C2 cells exposed to HG $(4.5 \mathrm{~g} / \mathrm{L}) . \mathrm{H} 9 \mathrm{C} 2$ cells were exposed to normal glucose (NG) or high glucose $(4.5 \mathrm{~g} / \mathrm{L})$ (HG) and subjected to $\mathrm{H} / \mathrm{R}$ in the absence or presence of propofol at concentrations 12.5 (P12.5), 25 (P25), 50 (P50), and $100 \mu \mathrm{M}$ (P100), or DMSO as control (D100). A: Mitochondria viability; B: Mitochondrial membrane potential assessed by JC-1 staining; C: Mitochondrial permeability transition pore (MPTP) opening; D: Mitochondrial cytochrome c protein expression; E: ATP content; F: Caveolin-3 (Cav-3) protein expression; G: Representative images of protein expression. Data are mean \pm SD with $\mathrm{n}=6$ per group, ${ }^{*} \mathrm{P}<0.05,{ }^{* *} \mathrm{P}<0.01$.
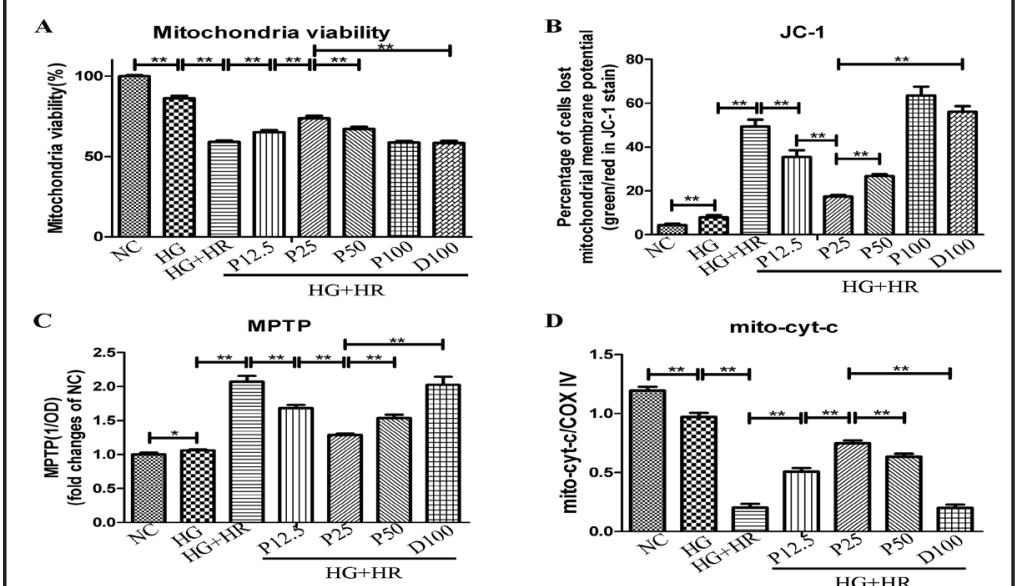

D
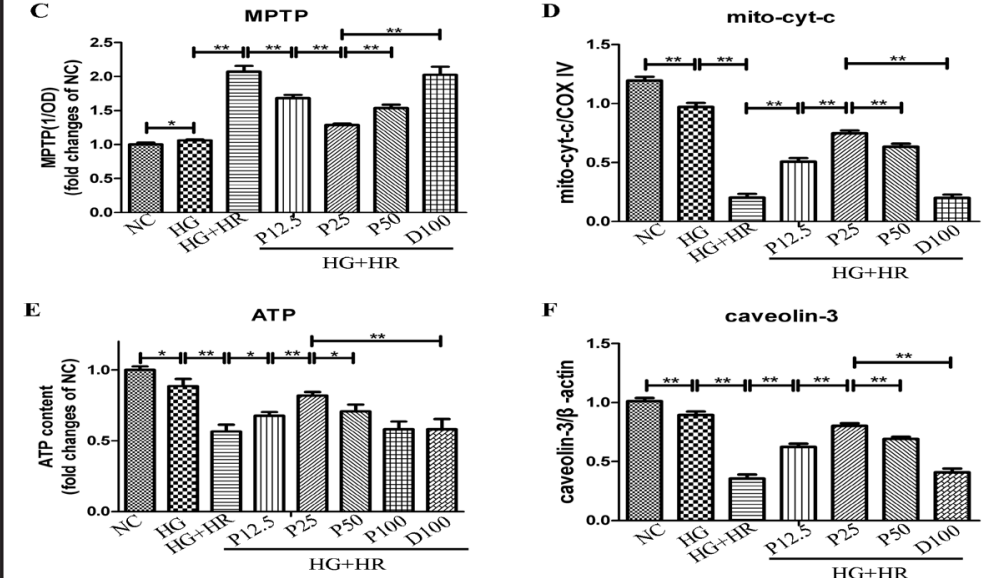

F

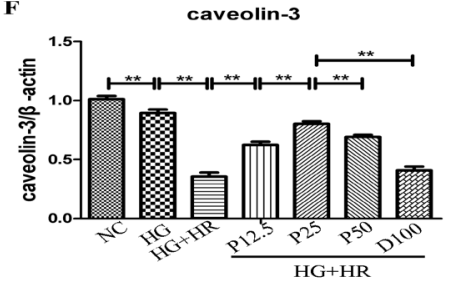

G

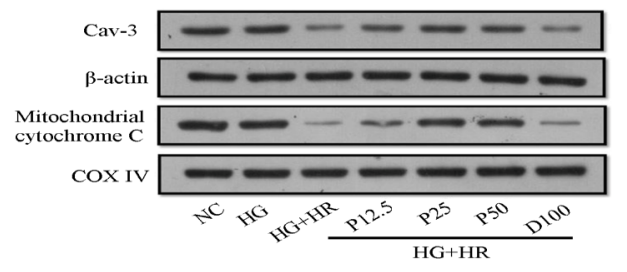

vs, HG, Fig. 4 E to G). However, when propofol concentration increased to $100 \mu \mathrm{M}$, no effect on mitochondrial function and biogenesis were observed. Thus, we chose $25 \mu \mathrm{M}$ of propofol in our ensuring experiments. 
Fig. 5. Disruption of caveolin-3 cancelled propofol cellular protection in $\mathrm{H} 9 \mathrm{C} 2$ cells. H9C2 cells were exposed to normal glucose (NG) or high glucose $(4.5 \mathrm{~g} / \mathrm{L})(\mathrm{HG})$ and subjected to $H / R$ in the absence or presence of propofol (P25, $25 \mu \mathrm{m}$ ) and caveolin-3 disruptor $\beta$-methyl-cyclodextrin (M- $\beta$-C). A: Cell viability; B: Lactate dehydrogenase (LDH); C: Creatine Kinase-MB (CK-MB); D: Cardiac troponin I (cTnI); E: Bax to Bcl2 ratio; F: Caspase-3 protein expression; G: Caspase-9 protein expression;H:Representative images of protein expression. Data are mean $\pm S D$ with $n=6$ per group, ${ }^{*} \mathrm{P}<0.05,{ }^{* *} \mathrm{P}<0.01$.

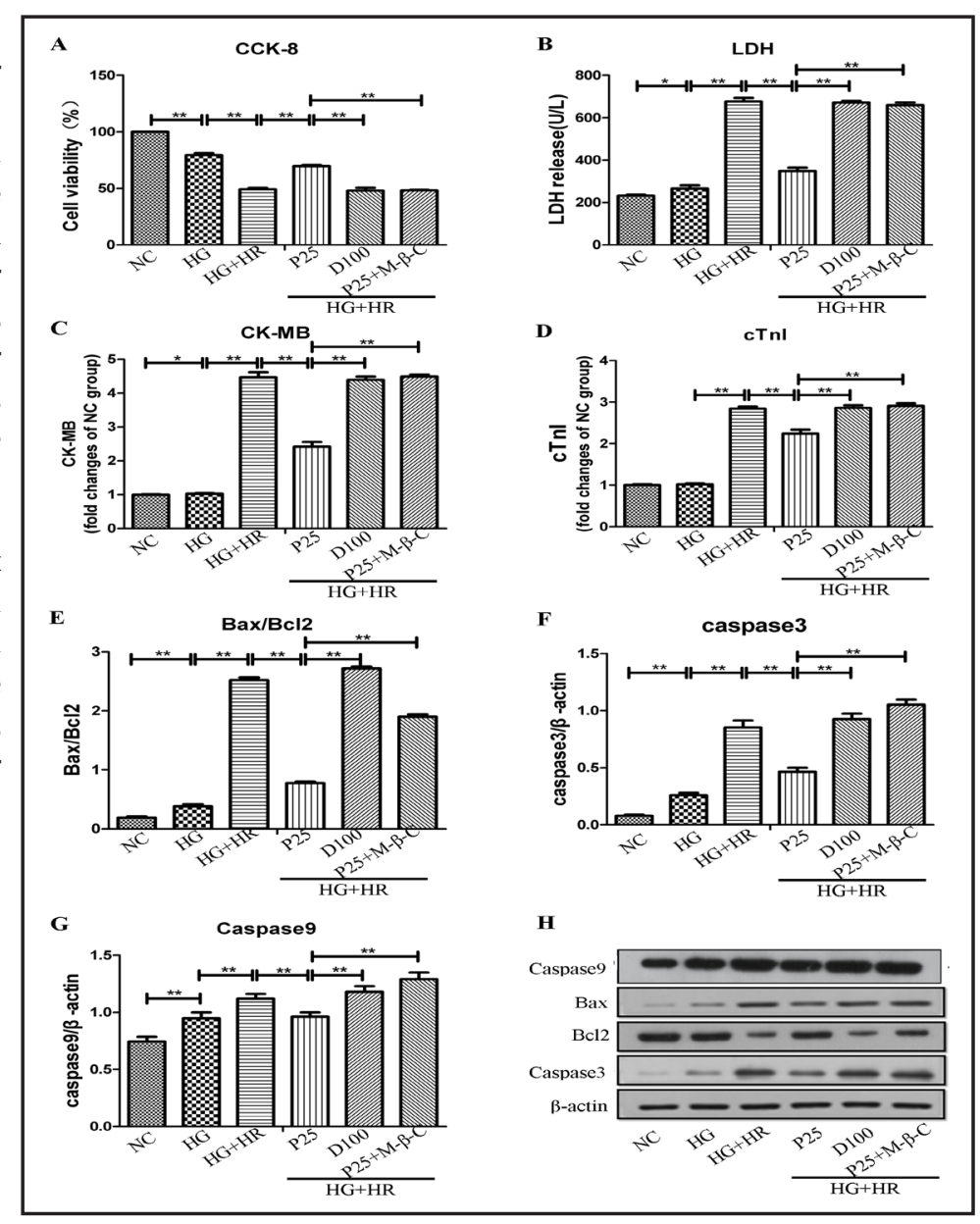

Disruption of Cav-3 cancelled propofol cellular protection against $H / R$ injury in cardiomyocytes exposed to high glucose

To investigate whether or not Cav-3 plays a critical role in propofol cellular protection in cardiomyocytes against H/R injury under HG, H9C2 cells were initially prepared as aforementioned and treated without or with the Cav- 3 disruptor methyl- $\beta$-cyclodextrin for 40 min before inducing hypoxia. As shown in Fig. 5, H/R under HG induced significant cell injury manifested as decreased cellular viability, increased LDH, enhanced CK-MB, and elevated cTnI (Fig. 5A-D) that were associated with increased cell apoptosis evidenced by increased Bax/Bcl-2 ratio and enhanced caspases-3 and caspase-9expression (Fig. 5E-G). All these changes were reversed/prevented by propofol, while the beneficial effects of propofol were cancelled by Cav-3 disruptor, methyl- $\beta$-cyclodextrin.

Disruption of Cav-3 cancelled propofol-mediated reduction of H/R-induced oxidative stress in cardiomyocytes exposed to high glucose

As shown in Fig. 6, H/R under HG induced significant increase of oxidative stress evidenced by increased ROS production (Fig. 6A-B), MDA formation (Fig. 6C), and reduced T-SOD (Fig. 6D). Propofol significantly attenuated H/R-induced oxidative stress while these effects of propofol were abolished by Cav-3 disruptor, methyl- $\beta$-cyclodextrin.

Disruption of Cav-3 cancelled propofol-mediated mitochondrial protection in cardiomyocytes exposed to high glucose and subjected to $H / R$

As shown in Fig. 7, H/R under HG significantly increased mitochondrial damage (decreased mitochondria viability, reduced mitochondrial membrane potential, increased 
Fig. 6. Disruption of caveolin-3 cancelled propofol protection in reducing oxidative stress in H9C2 cells. H9C2 cells were exposed to normal glucose (NG) or high glucose (4.5 g/L) (HG) and subjected to $H / R$ in the absence or presence of propofol (P25, 25 $\mu \mathrm{m})$ and caveolin-3 disruptor $\beta$-methyl-cyclodextrin (M- $\beta-\mathrm{C}$ ). $A$ and B: ROS formation assessed by DCF-DA fluorescence staining; C: Level of malondialdehyde (MDA); D: Total superoxide dismutase (T-SOD) activity. Data are mean \pm SD with $\mathrm{n}=6$ per group, * $\mathrm{P}<0.05$, ** $\mathrm{P}<0.01$.

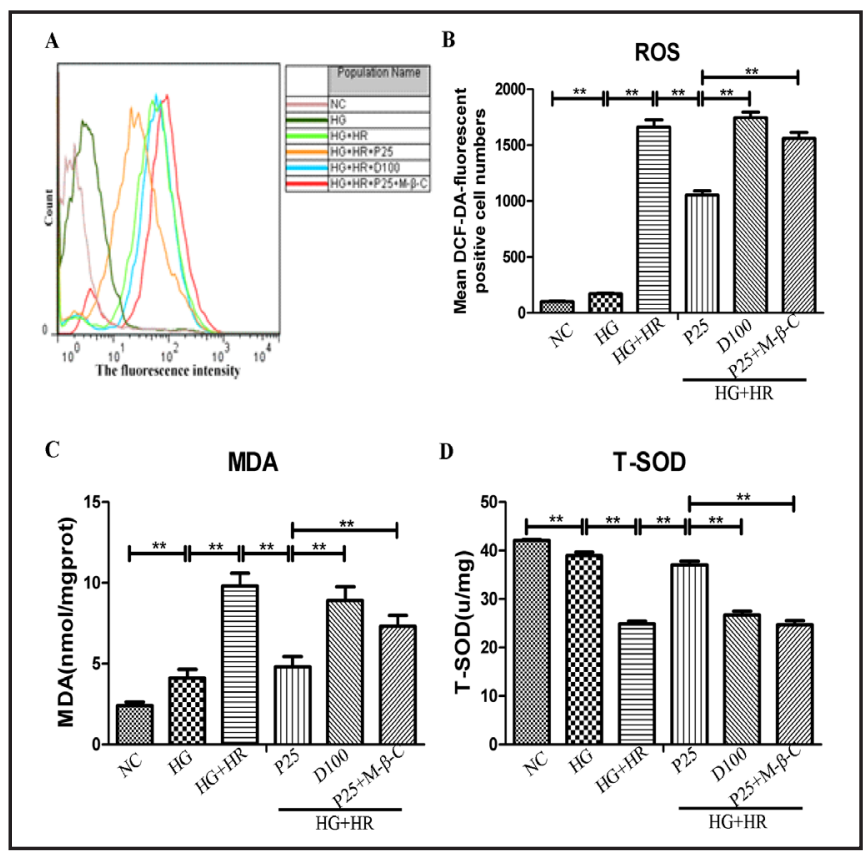

Fig. 7. Disruption of caveolin-3 cancelled propofol protection in attenuating mitochondrial function in $\mathrm{H} 9 \mathrm{C} 2$ cells. H9C2 cells were exposed to normal glucose (NG) or high glucose (4.5 g/L) (HG) and subjected to $\mathrm{H} / \mathrm{R}$ in the absence or presence of propofol (P25, 25 $\mu \mathrm{m})$ and caveolin-3 disruptor $\beta$-methylcyclodextrin (M- $\beta-\mathrm{C})$. A: Mitochondria viability; $B$ : Mitochondrial membrane potential assessed by JC-1 staining; C: Mitochondrial permeability transition pore (MPTP) opening; D: Mitochondrial cytochrome c protein expression; E: ATP content; F: Caveolin-3 (Cav-3) protein expression; G: Representative images of protein expression. Data are mean \pm SD with $\mathrm{n}=6$ per group, ${ }^{*} \mathrm{P}<0.05,{ }^{* *} \mathrm{P}<0.01$.

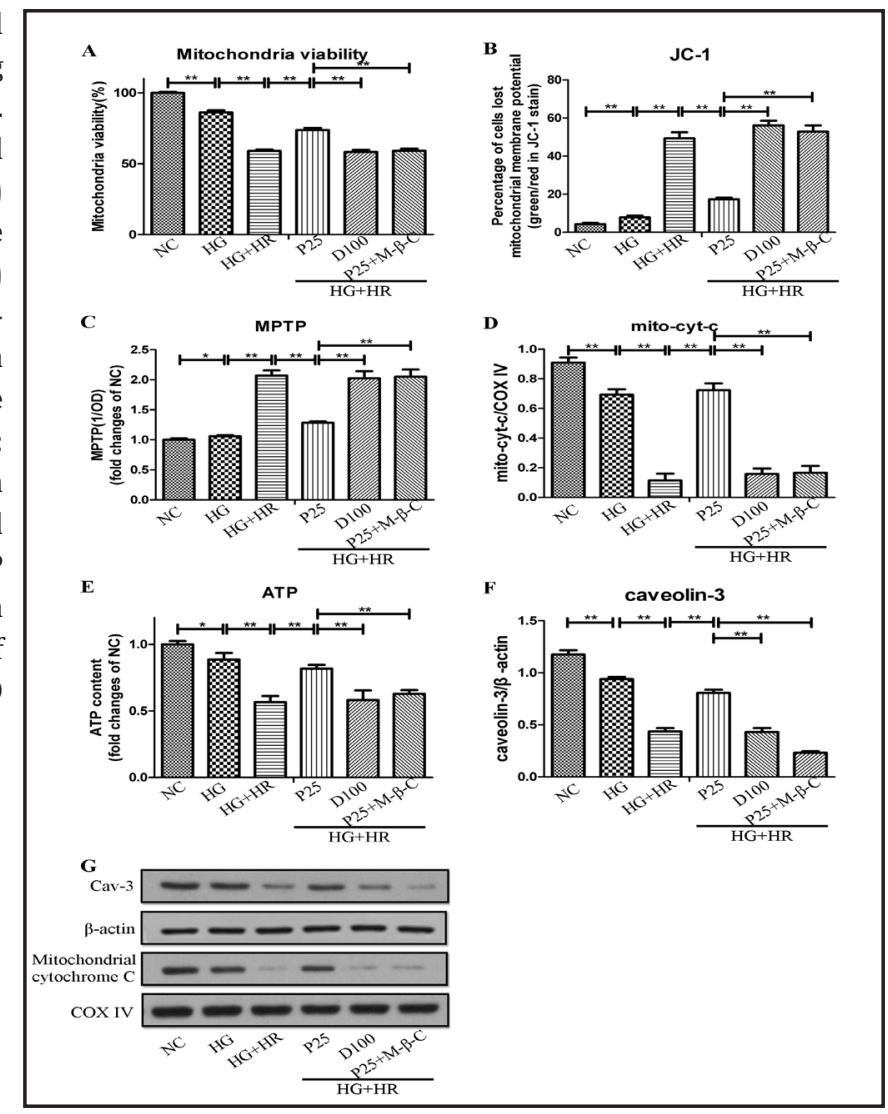

MPTP opening, and elevated mitochondrial cytochrome C release/reduced mitochondrial cytochrome $\mathrm{C}$ content) and reduced mitochondrial biogenesis (decreased ATP production) (Fig. 7A-E), which were associated with reduced Cav-3 protein expression (Fig. 7F). All these changes were attenuated by propofol, while these beneficial effects of propofol were cancelled by Cav-3 disruption with methyl- $\beta$-cyclodextrin. 


\section{Cellular Physiology

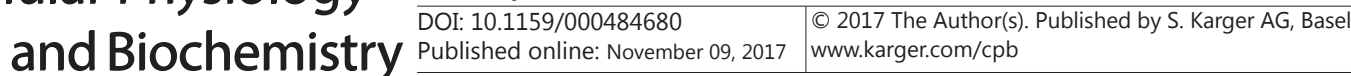 \\ Deng et al.: Propofol Upregulates Cardiomyocyte Post-Hypoxic Caveolin-3}

Fig. 8. Disruption of caveolin-3 cancelled propofol induced Akt and STAT3 activation in H9C2 cells. H9C2 cells were exposed to normal glucose (NG) or high glucose (4.5 g/L) (HG) and subjected to H/R in the absence or presence of propofol (P25, 25 $\mu \mathrm{m})$ and caveolin-3 disruptor $\beta$-methyl-cyclodextrin (M- $\beta-\mathrm{C})$. A: Representative images of protein expression; B: Akt protein expression; C: STAT3 protein expression. Data are mean \pm SD with $\mathrm{n}=6$ per group, ${ }^{*} \mathrm{P}<0.05$, ${ }^{* *} \mathrm{P}<0.01$.

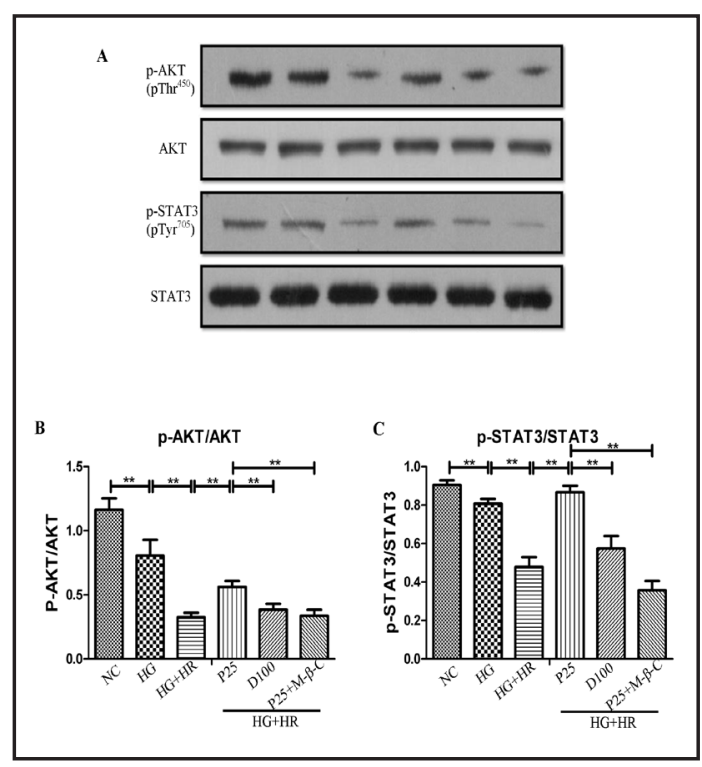

Propofol conferred cellular protection by increasing Akt and STAT3 activation through Cav-3

As shown in Fig. 8, HG exposure significantly decreased Akt (Thr450) and STAT3 (Tyr705) phosphorylation/activation (Fig. 8A-C), which were further decreased by H/R. Propofol significantly attenuated HG and HR induced reductions in Akt and STAT3 activation, while these effects of propofol were cancelled by Cav- 3 disruption with methyl- $\beta$-cyclodextrin (Fig. 8A-C).

\section{Discussion}

The hearts from diabetic subjects are more susceptible to ischemia reperfusion injury but less or not responsive to cardioprotective interventions that are effective in non-diabetic subjects, and the underlying mechanism is incompletely understood. Recent studies have demonstrated that caveolae and caveolin play important roles in signal transduction of myocardial cells $[25,26]$. Cav-3 is an essential protein to the function implementation of caveolae in myocardial cells $[12,27]$, and Cav-3 is highly expressed in myocardial cells that has protective effects on myocardial cells in case of I/R [20]. Our study showed that when the cardiomyocytes were exposed to high glucose for a long time (48 h), expression of Cav-3 decreased significantly. However, some studies showed that when the myocardial cells were exposed to high glucose for a short duration (6-12h), expression of Cav-3 in myocardial cells increased [28]. It is believed that the myocardial cells regulate the expression of Cav-3 as the acute stress reaction for self-protection when being exposed to high glucose. A number of in vitro and in vivo studies have confirmed that when the cardiomyocytes are exposed to high glucose for a long time, expression of Cav-3 decreases, and the activation of protein kinase $\mathrm{C}$ (PKC) $\beta 2$ is closely related to the expression of Cav-3 in myocardial cells under high glucose $[20,29]$. The findings of current study is in line with a recent study conducted by our group showing that long time exposure of cardiomyocyte to high glucose resulted in reduction in Cav3 expression. However, it is yet to be explored whether or not high glucose induced reduction in cardiomyocyte Cav-3 expression is a mechanism that rendered the cardiomyocytes more susceptible to ischemia/reperfusion or hypoxia/reoxygenation injury, and whether or not therapies that may enhance cardiomyocyte Cav-3 expression can attenuate myocardial I/R injury in diabetes or under conditions of high glucose stimulation. Our findings that propofol can enhance Cav-3 expression during H/R under high glucose condition and that Cav-3 inhibition can completely cancelled the beneficial effects of propofol indicate that Cav- 


\section{Cellular Physiology \begin{tabular}{l|l|l} 
DOI: $10.1159 / 000484680$ & (c) 2017 The Author(s). Published by S. Karger AG, Basel \\
www.karger.com/cpb
\end{tabular} \\ Deng et al.: Propofol Upregulates Cardiomyocyte Post-Hypoxic Caveolin-3}

3 activation is a major mechanism by which propofol confers cardioprotection. It should be noted that under high glucose condition, caveolin disruption could reduce the activation of cardiomyocyte p-Akt [20], a key protein of the pro-survival signaling pathway, in the absence of hypoxia/reoxygenation. Therefore, application the caveolin disruptor methyl- $\beta$ cyclodextrin per se, as used in our current study, should have potentially exacerbated posthypoxic cardiomyocyte injury. Nevertheless, the fact propofolcan enhance post-hypoxic cardiomyocyte Cav- 3 and that application of methyl- $\beta$-cyclodextrin completely cancelled the cellular protective effects of propofol against hypoxia/reoxygenation injury should be sufficient to confirm that Cav-3 activation is a major mechanism by which propofol confers cardioprotection under high glucose condition. Further study shall be designed to explore Cav-3 distribution in cardiomyocytes and the impact of propofol, in particular in vivo models of myocardial I/R in diabetes or under hyperglycemic conditions in the absence or presence of Cav-3 siRNA gene knock down to further confirm the role of Cav-3 in propofol cardioprotection.

The intravenous anesthetic propofol has recently been shown to attenuate post-ischemic myocardial injury in diabetic patients undergoing cardiac surgery [5], but the underlying mechanism has not been explored. In order to exclude the interference of fat emulsion solvent of propofol on experimental results, pure propofol powder was used. DMSO solvent was used to dissolve the propofol powder, and then diluted to ensure that the concentration of DMSO would not damage the cells and affect our experimental results. It was reported that DMSO could alleviate the damage of ROS to cells [30]. However, DMSO, at the concentration needed to dissolve propofol as used in our experiment did not demonstrate the above mentioned beneficial effects, indicating that the beneficial effects observed are solely the effects of propofol. A number of studies also show that [31, 32], DMSO does not significantly alleviate the damage of ROS to cells in case of cell I/R injury. In addition, our study showed that $25 \mu \mathrm{mol} / \mathrm{L}$ propofol applied during reoxygeration generates the maximal protective effect on myocardial cells against post-hypoxic cellular injury, while some studies showed that $50 \mu \mathrm{mol} / \mathrm{L}$ propofol or even $100 \mu \mathrm{mol} / \mathrm{L}$ propofol generate better protective effect on cells in case of I/R [33, 34]. It was believed that these differences are caused by different factors, such as cell model, cell type and experimental environment.

\section{Conclusion}

Our study showed that propofol post conditioning can attenuate cardiomyocyte $H / R$ injury under HG and reduce post-hypoxic cardiomyocyte apoptosis through reducing the activation of the pro-apoptotic caspase-3 that was downstream of the pro-apoptotic caspase 8 and 9 in cardiomyocytes subjected to hypoxia/reoxygenation [35], with upregulating the expression of Cav-3 as the major mechanism of propofol cardioprotection. To the best of our knowledge, this is the first study to report that Cav-3 is a key molecule for propofol to confer cardioprotection under conditions of high glucose stimulation. Further in vivo studies in diabetic models or in patients are needed to verify the mechanistic findings gained from the current study.

\section{Acknowledgements}

This study was supported by grants from National Natural Science Foundation of China (NSFC, 81270899, 81670770), Science and Technology Project Foundation of Guangdong Province, China (No. 2013B031800015) and Natural Science foundation of Hubei Province grant (2014CFC1028) and Research Grants Council (RGC) /GRF grant (17123915M). The Authors wish to acknowledge Shenzhen IVY-Valued Biotechnology Co., Ltd for technique assistance and acknowledge Van Scholar Editors Co., Ltd., Vancouver, Canada, for English language editing.

\section{KARGER}




\section{Cellular Physiology Cell Physiol Biochem 2017;44:279-292 \begin{tabular}{l|l|l} 
and Biochemistry.1159/000484680 & $\begin{array}{l}\text { (c) 2017 The Author(s). Published by S. Karger AG, Basel } \\
\text { www.karger.com/cpb }\end{array}$ \\
\hline Published online: November 09, 2017
\end{tabular} \\ Deng et al.: Propofol Upregulates Cardiomyocyte Post-Hypoxic Caveolin-3}

\section{Disclosure Statement}

None.

\section{References}

1 Chen C, Chen W, Nong Z, Ma Y, Qiu S, Wu G: Cardioprotective effects of combined therapy with hyperbaric oxygen and diltiazem pretreatment on myocardial ischemia-reperfusion injury in rats. Cell Physiol Biochem 2016;38:2015-2029.

-2 Yu H, Zhang H, Zhao W, Guo L, Li X, Li Y, Zhang X, Sun Y: Gypenoside protects against myocardial ischemiareperfusion injury by inhibiting cardiomyocytes apoptosis via inhibition of chop pathway and activation of pi3k/akt pathway in vivo and in vitro. Cell Physiol Biochem 2016;39:123-136.

-3 Li Y, Zhong D, Lei L, Jia Y, Zhou H, Yang B: Propofol prevents renal ischemia-reperfusion injury via inhibiting the oxidative stress pathways. Cell Physiol Biochem 2015;37:14-26.

4 Xu Z, Yu J, Wu J, Qi F, Wang H, Wang Z, Wang Z: The effects of two anesthetics, propofol and sevoflurane, on liver ischemia/reperfusion injury. Cell Physiol Biochem 2016;38:1631-1642.

5 Ansley DM, Raedschelders K, Choi PT, Wang B, Cook RC, Chen DD: Propofol cardioprotection for on-pump aortocoronary bypass surgery in patients with type 2 diabetes mellitus (pro-tect ii): A phase 2 randomizedcontrolled trial. Can J Anaesth 2016;63:442-453.

6 Xia Z, Godin DV, Chang TK, Ansley DM: Dose-dependent protection of cardiac function by propofol during ischemia and early reperfusion in rats: Effects on 15-f2t-isoprostane formation. Can J Physiol Pharmacol 2003;81:14-21.

7 Xia Z, Godin DV, Ansley DM: Propofol enhances ischemic tolerance of middle-aged rat hearts: Effects on 15-f(2t)-isoprostane formation and tissue antioxidant capacity. Cardiovasc Res 2003;59:113-121.

$>8$ Zhou T, Chuang CC, Zuo L: Molecular characterization of reactive oxygen species in myocardial ischemiareperfusion injury. Biomed Res Int 2015;2015:864946.

-9 Buja LM, Vander Heide RS: Pathobiology of ischemic heart disease: Past, present and future. Cardiovasc Pathol 2016;25:214-220.

10 Lemoine S, Zhu L, Gress S, Gerard JL, Allouche S, Hanouz JL: Mitochondrial involvement in propofolinduced cardioprotection: An in vitro study in human myocardium. Experimental biology and medicine 2016;241:527-538.

11 Sirvinskas E, Kinderyte A, Trumbeckaite S, Lenkutis T, Raliene L, Giedraitis S, Macas A, Borutaite V: Effects of sevoflurane vs. Propofol on mitochondrial functional activity after ischemia-reperfusion injury and the influence on clinical parameters in patients undergoing cabg surgery with cardiopulmonary bypass. Perfusion 2015;30:590-595.

12 Balijepalli RC, Kamp TJ: Caveolae, ion channels and cardiac arrhythmias. Prog Biophys Mol Biol 2008;98:149-160.

13 Tang W, Feng X, Zhang S, Ren Z, Liu Y, Yang B, lv B, Cai Y, Xia J, Ge N: Caveolin-1 confers resistance of hepatoma cells to anoikis by activating igf-1 pathway. Cell Physiol Biochem 2015;36:1223-1236.

14 Sun J, Kohr MJ, Nguyen T, Aponte AM, Connelly PS, Esfahani SG, Gucek M, Daniels MP, Steenbergen C, Murphy E: Disruption of caveolae blocks ischemic preconditioning-mediated s-nitrosylation of mitochondrial proteins. Antioxid Redox Signal 2012;16:45-56.

15 Zhao J, Wang F, Zhang Y, Jiao L, Lau WB, Wang L, Liu B, Gao E, Koch WJ, Ma XL, Wang Y: Sevoflurane preconditioning attenuates myocardial ischemia/reperfusion injury via caveolin-3-dependent cyclooxygenase-2 inhibition. Circulation 2013;128:S121-129.

-16 Wang J, Schilling JM, Niesman IR, Headrick JP, Finley JC, Kwan E, Patel PM, Head BP, Roth DM, Yue Y, Patel $\mathrm{HH}$ : Cardioprotective trafficking of caveolin to mitochondria is gi-protein dependent. Anesthesiology 2014;121:538-548.

17 See Hoe LE, Schilling JM, Tarbit E, Kiessling CJ, Busija AR, Niesman IR, Du Toit E, Ashton KJ, Roth DM, Headrick JP, Patel HH, Peart JN: Sarcolemmal cholesterol and caveolin-3 dependence of cardiac function, ischemic tolerance, and opioidergic cardioprotection. Am J Physiol Heart Circ Physiol 2014;307:H895-903.

18 Grim KJ, Abcejo AJ, Barnes A, Sathish V, Smelter DF, Ford GC, Thompson MA, Prakash YS, Pabelick CM: Caveolae and propofol effects on airway smooth muscle. Br J Anaesth 2012;109:444-453. 


\section{Cellular Physiology Cell Physiol Biochem 2017;44:279-292

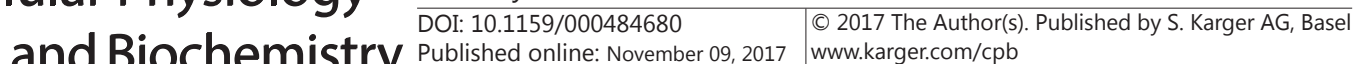 and Biochemistry

19 Penumathsa SV, Thirunavukkarasu M, Samuel SM, Zhan L, Maulik G, Bagchi M, Bagchi D, Maulik N: Niacin bound chromium treatment induces myocardial glut-4 translocation and caveolar interaction via akt, ampk and enos phosphorylation in streptozotocin induced diabetic rats after ischemia-reperfusion injury. Biochim Biophys Acta 2009;1792:39-48.

-20 Lei S, Li H, Xu J, Liu Y, Gao X, Wang J, Ng KF, Lau WB, Ma XL, Rodrigues B, Irwin MG, Xia Z: Hyperglycemiainduced protein kinase $\mathrm{c}$ beta2 activation induces diastolic cardiac dysfunction in diabetic rats by impairing caveolin-3 expression and akt/enos signaling. Diabetes 2013;62:2318-2328.

-21 Liu Y, Jin J, Qiao S, Lei S, Liao S, Ge ZD, Li H, Wong GT, Irwin MG, Xia Z: Inhibition of pkcbeta2 overexpression ameliorates myocardial ischaemia/reperfusion injury in diabetic rats via restoring caveolin-3/akt signaling. Clinical science 2015;129:331-344.

-22 Li H, Yao W, Liu Z, Xu A, Huang Y, Ma XL, Irwin MG, Xia Z: Hyperglycemia abrogates ischemic postconditioning cardioprotection by impairing adipor1/caveolin-3/stat3 signaling in diabetic rats. Diabetes 2016;65:942-955.

23 Jiang Y, Zhou Z, Meng QT, Sun Q, Su W, Lei S, Xia Z, Xia ZY: Ginsenoside rb1 treatment attenuates pulmonary inflammatory cytokine release and tissue injury following intestinal ischemia reperfusion injury in mice. Oxid Med Cell Longev 2015;2015:84721.

24 Li H, Yao W, Irwin MG, Wang T, Wang S, Zhang L, Xia Z: Adiponectin ameliorates hyperglycemia-induced cardiac hypertrophy and dysfunction by concomitantly activating nrf2 and brg1 Free Radic Biol Med 2015;84:311-321.

25 Chaudhary KR, Cho WJ, Yang F, Samokhvalov V, El-Sikhry HE, Daniel EE, Seubert JM: Effect of ischemia reperfusion injury and epoxyeicosatrienoic acids on caveolin expression in mouse myocardium. J Cardiovasc Pharmacol 2013;61:258-263.

-26 Roth DM, Patel HH: Role of caveolae in cardiac protection. Pediatr Cardiol 2011;32:329-333.

-27 Schilling JM, Roth DM, Patel HH: Caveolins in cardioprotection - translatability and mechanisms. Br J Pharmacol 2015;172:2114-2125.

-28 Gomez-Ruiz A, de Miguel C, Campion J, Martinez JA, Milagro FI: Time-dependent regulation of muscle caveolin activation and insulin signalling in response to high-fat diet. FEBS letters 2009;583:3259-3264.

-29 Woodman SE, Park DS, Cohen AW, Cheung MW, Chandra M, Shirani J, Tang B, Jelicks LA, Kitsis RN, Christ GJ, Factor SM, Tanowitz HB, Lisanti MP: Caveolin-3 knock-out mice develop a progressive cardiomyopathy and show hyperactivation of the p42/44 mapk cascade. J Biol Chem 2002;277:38988-38997.

-30 Elisia I, Nakamura H, Lam V, Hofs E, Cederberg R, Cait J, Hughes MR, Lee L, Jia W, Adomat HH, Guns ES, McNagny KM, Samudio I, Krystal G: Dmso represses inflammatory cytokine production from human blood cells and reduces autoimmune arthritis. PLoS One 2016;11:e0152538.

-31 Xie CL, Pan YB, Hu LQ Qian YN: Propofol attenuates hydrogenperoxide-induced apoptosis in human umbilical vein endothelial cells via multiple signaling pathways. Korean J Anesthesiol 2015;68:488-495.

-32 Chen Z, Hu Z, Lu Z, Cai S, Gu X, Zhuang H, Ruan Z, Xia Z, Irwin MG, Feng D, Zhang L: Differential microrna profiling in a cellular hypoxia reoxygenation model upon posthypoxic propofol treatment reveals alterations in autophagy signaling network. Oxid Med Cell Longev 2013;2013:378484.

-33 Guo YQ, Zheng LN, Wei JF, Hou XL, Yu SZ, Zhang WW, Jing JM: Expression of ccl2 and ccr2 in the hippocampus and the interventional roles of propofol in rat cerebral ischemia/reperfusion. Exp Ther Med 2014;8:657-661.

-34 Cui D, Wang L, Qi A, Zhou Q Zhang X, Jiang W: Propofol prevents autophagic cell death following oxygen and glucose deprivation in pc12 cells and cerebral ischemia-reperfusion injury in rats. PloS One 2012;7:e35324.

-35 Chao W, Shen Y, Li L, Rosenzweig A: Importance of fadd signaling in serum deprivation- and hypoxiainduced cardiomyocyte apoptosis. J Biol Chem 2002;277:31639-31645. 